\title{
A COPD Health Management Program in a Community-Based Primary Care Setting: A Randomized Controlled Trial
}

\author{
Peian Lou PhD, Peipei Chen PhD, Pan Zhang MPH, Jiaxi Yu PhD, Yong Wang MD, \\ Na Chen PhD, Li Zhang PhD, Hongmin Wu MD, and Jing Zhao MD
}

\begin{abstract}
BACKGROUND: A number of effective strategies have been developed to improve the quality of life in patients with COPD. However, few have been implemented in patients with COPD at all stages in a community setting. This study evaluated the efficacy of a complex COPD health management intervention in rural communities in China. METHODS: A randomized controlled trial including 8,217 subjects with COPD was implemented from May 2008 to May 2012 in 14 community health-care centers. The control group of subjects received usual care, whereas the management group of subjects participated in a health management program that included assessing the subjects' health status, giving regular health lectures, smoking cessation counseling, encouraging regular exercise, providing rehabilitative training and psychological counseling, and regular followup. As a primary outcome, we examined the changes in the BODE index. Secondary outcomes included depression and anxiety rates, current smoking rate, awareness of COPD, mortality, risk factors, respiratory medication use, hospital admissions, and emergency department visits. RESULTS: After $4 \mathrm{y}$, the mean cumulative value of the BODE index increased by 0.7 per subject in the control group and decreased by 0.4 per subject in the health management group (difference of $1.1,95 \%$ CI $0.2-2.0, P<.001$ ). Health management reduced anxiety symptoms by $4.8 \%$, depression symptoms by $6.6 \%$, current smoking by $14.3 \%$, mortality due to all causes by $9.0 \%$, hospitalizations due to all causes by $\mathbf{1 6 . 1 \%}$, and emergency department visits due to all causes by 18.1\% ( $P<.05$ for all). However, it increased immunomodulator use by $58.9 \%$, respiratory medication use by 14.1-21.9\%, and awareness scores for COPD by $57.2 \%(P<.05$ for all). CONCLUSIONS: The health management program is an effective community-based strategy for the prevention and management of COPD in China, increasing awareness and knowledge among patients and practitioners and improving management within the limitations of access to pharmacotherapy. Key words: COPD; health management; BODE index; health status. [Respir Care 2015;60(1):102-112. (C) 2015 Daedalus Enterprises]
\end{abstract}

\section{Introduction}

COPD is increasingly recognized as a systemic disease. ${ }^{1}$ Prescribing medication alone usually fails to produce the optimal outcome for patients with COPD. ${ }^{2}$ Instead, multi-

Drs Lou, Chen, Yu, Wang, Chen, and Zhang and Mr Zhang are affiliated with the Department of Control and Prevention of Chronic Non-communicable Diseases, Xuzhou Center for Disease Control and Prevention, Xuzhou, China. Drs Wu and Zhao are affiliated with the Department of Respiratory Medicine, Affiliated Hospital of Xuzhou Medical College, Xuzhou, China.

Supplementary material related to this paper is available at http:// www.rcjournal.com. dimensional approaches are recommended for COPD treatment. ${ }^{3-6}$ These programs lead to improvements in dyspnea, health-related quality-of-life outcomes, health-care utiliza-

\footnotetext{
This study was funded by the Science and Technology Projects of Xuzhou City in 2007 (XM07C037). The researchers were independent of funding organizations. The authors have disclosed no conflicts of interest.

Correspondence: Peian Lou PhD, Department of Control and Prevention of Chronic Non-communicable Diseases, Xuzhou Center for Disease Control and Prevention, 142 West Erhuan Rd, Xuzhou City 221006, Jiangsu Province, China. E-mail: 1pa82835415@126.com.
}

DOI: $10.4187 /$ respcare. 03420 
tion, and psychosocial outcomes, as well as reductions in hospitalizations and emergency department visits. ${ }^{7-9}$

However, these effective management strategies for COPD are employed mainly by specialists in integrated medical facilities, not by general practitioners and healthcare workers in health-care units. ${ }^{4-6}$ Limited attention has been paid to community-based management of patients at different stages of COPD on a large scale, particularly those living in the rural areas of China.

The goal of health management is to direct the limited resources available for chronic disease management to patients with the greatest need for improvement. The programs of health management may include collecting health information, conducting a periodic health examination with a general initial medical diagnosis, confirming risk factors and risk assessment, management of risk factors (including education about disease, optimization of evidence-based medications, providing information and support from case managers, and instilling self-management principles), longterm tracking, and follow-up and repetition of the above steps. Health management programs have been successfully implemented for chronic conditions, such as hypertension and diabetes mellitus. ${ }^{10}$ However, effective evidence that health management improves COPD care is lacking. Therefore, a model for managing the care of patients with COPD is still needed. The aim of such a model would be to integrate available health-care resources and help the various clinicians involved to agree on a common approach and act in concert. We therefore sought to determine whether a simpler health management program, with a focus on behavioral intervention and rehabilitation training, would improve outcomes in patients with COPD.

In this study, we established a 4-y community-based health management intervention program ${ }^{6}$ and evaluated its efficacy for improving the health status of patients with COPD by monitoring a number of relevant indices, such as the BODE (body mass index [B], degree of air-flow obstruction [O], level of functional dyspnea [D], and exercise capacity [E]) index. We wanted to develop and validate a reliable strategy for effective COPD management in the community setting.

\section{Methods}

\section{Study Design}

This community-based, parallel-group, pragmatic, randomized controlled trial involving 2 groups of subjects with COPD ran at 14 health-care units from May 2008 to May 2012 in rural areas of Xuzhou City, China. The first group participated in a health management program for $4 \mathrm{y}$. The second group received usual care for $4 \mathrm{y}$. Recruitment of health-care centers took place in 28 communities based on our previous epidemiological study. ${ }^{11}$

\section{QUICK LOOK}

\section{Current knowledge}

COPD has been increasingly recognized as a systemic disease with multisystem involvement. Multidimensional approaches are recommended for management of the disease. These programs lead to improvements in dyspnea, health-related quality-of-life outcomes, healthcare utilization, and reductions in hospitalizations and emergency department visits.

\section{What this paper contributes to our knowledge}

A health management program including assessing health status of subjects, giving regular health lectures, smoking cessation counseling, encouraging regular exercise, rehabilitative training, psychological counseling, and regular follow-up was an effective community-based strategy for the prevention and management of COPD in China. Increased awareness and knowledge among patients and practitioners were effective in an environment with limited access to pharmacotherapy.

Health-care centers were classified into 2 groups: those with previous experience with health management counseling and those without. Centers with experience and those without were then randomly allocated separately into the health management and control groups to prevent an imbalance between interventions in centers with previous experience. To detect a $25 \%$ relative reduction in the primary outcome between the 2 groups with $80 \%$ power, a 2-sided type-1 error of 5\%, a design effect of 2.5 , and an intracluster correlation coefficient of 0.03 , we determined from a pilot study that we needed 7 centers with a total of at least 3,300 subjects in each group according to the usual formula, allowing for $20 \%$ loss during follow-up.

There are no geographical differences between these communities. A health-care unit is a typical office unit in the community. None of the observation areas had air pollution according to data provided by the environmental protection department.

This study was approved by the ethics committee of the Xuzhou Center for Disease Control and Prevention and the regional ethical vetting board in Xuzhou, China. Agreement was received from all relevant medical units. Informed consent was obtained from all subjects. This is Chinese Clinical Trial Registry ChiCTR-TRC-12001958.

\section{Study Population}

Subjects were recruited by their family physicians from 14 health-care centers in rural areas of Xuzhou City, China, from January to March 2008. At baseline, the subjects had 
to have a diagnosis of COPD according to the criteria proposed by the Global Initiative for Chronic Obstructive Lung Disease (GOLD). ${ }^{12}$ The following exclusion criteria were used to minimize selection bias by the County People's Hospital: presence of fever, active tuberculosis, changes in radiographic images or medication in the 4 weeks immediately preceding recruitment, primary diagnosis of asthma or obvious bronchiectasis, cystic fibrosis, interstitial lung disease, previous lung-volume-reduction surgery, lung transplantation, pneumonectomy, uncontrolled or serious conditions that could potentially affect spirometry tests, and refusal to fill out psychological questionnaires. The subjects completed questionnaires and underwent spirometry testing at both the baseline assessment and at the end of the follow-up assessments. General characteristics were documented based on subject reports. Weight and height were measured before pulmonary function tests were conducted. All qualified candidates were invited to participate in the study during home visits. All subjects were of Han ancestry and had the same cultural background and dietary habits. The subjects underwent follow-up interviews with questionnaires and spirometry tests in the same health-care centers for both baseline and follow-up surveys. The end points were the last follow-up results of each subject. Subjects were lost to follow-up if we could not contact them or if they moved to another location, withdrew consent, refused to proceed, had invalid data, or were unable to complete the study.

\section{Intervention}

One-hundred thirty-six general practitioners, working at 7 different health-care centers, in the management group took $2 \mathrm{~d}$ of training in health management for intervention. The training included: general information about COPD, pathogenesis, risk factors, clinical manifestations, assessment of subjects' conditions, display of exacerbation, and the stable stage of treatment and rehabilitation of COPD. In addition, they learned the follow-up process, how to help subjects quit smoking, and how to help subjects improve self-management skills.

Subjects in the management group participated in the health management program, which was delivered in these 7 health-care centers. Full details on the health management program are provided in Appendix 1 (see the supplementary materials at http://www.rcjournal.com).

The health management strategies included the following steps. (1) Data from the initial investigation were used to assess the baseline characteristics of the study subjects. (2) A health management plan was designed for each subject in the management group. (3) Every 2 weeks, subjects were given a lecture that lasted for $40-60 \mathrm{~min}$ and included general information about COPD, direct observation of inhaler techniques, a review and adjustment of out-patient COPD medications, smoking cessation counseling, recommendations concerning influenza and pneumococcal vaccinations, encouragement for regular exercise, instruction on hand hygiene, rehabilitation, and psychological counseling. All subjects were asked to participate in the lectures along with their caregivers. The health education materials, which contained the content of the 48 total lectures, were distributed to the subjects and their physicians. (4) General practitioners who participated in this study were trained according to GOLD guidelines and health management content. (5) Every 2 weeks, general practitioners conducted at least one face-to-face follow-up visit, which took place either at the subject's home or at the health-care centers to assess the subject's compliance with the doctor's orders. The general practitioners filed a monthly report on the condition of each subject for a team of professionals. (6) The professionals assessed those reports and selected a topic of focus for each subject. The assessments were then returned to the general practitioners. This recording and feedback system was designed for continued improvement of the follow-up procedure. (7) Every 2 months, the professionals, including pulmonologists, psychiatrists, rehabilitation specialists, nutritionists, respiratory nurses, and other experts, examined the subjects collectively at the health-care units. The professionals also supervised the frequency and quality of the general practitioners' follow-up practices.

\section{Usual Care}

Health-care providers and general practitioners provided subjects in the control group with usual care according to the subjects' needs. Every 2 months, the caregivers were asked to determine each subject's condition by telephone or at a face-to-face follow-up visit, record the subject's status at the health-care stations, and then report this information to our study group. In case of deterioration, subjects were treated with drugs in accordance with the GOLD guidelines or referred to a respiratory specialist. The content and frequency of usual care services were not standardized.

\section{Outcome Measures}

The primary end point used to evaluate subjects' health status was the BODE index. ${ }^{13}$ Briefly, pulmonary function was assessed based on the standards set forth by the American Thoracic Society. ${ }^{14}$ Dyspnea was measured according to the Modified Medical Research Council (MMRC) dyspnea scale, ${ }^{15}$ in which higher scores indicate more severe dyspnea. The 6-min walk test (6MWT) was carried out according to American Thoracic Society guidelines. ${ }^{14}$ Each of these BODE variables was assigned a specific index value, and from these, the total score was calculated, rang- 
Table 1. Baseline Characteristics of Health-Care Units

\begin{tabular}{lcc}
\hline \hline \multicolumn{1}{c}{ Variable } & $\begin{array}{c}\text { Intervention } \\
\text { Community }\end{array}$ & $\begin{array}{c}\text { Control } \\
\text { Community }\end{array}$ \\
\hline Units, $n$ & 7 & 7 \\
Population, $n$ & 301,785 & 298,467 \\
Annual per capita income & $21,345 \pm 464$ & $21,545 \pm 471$ \\
$\quad$ (mean \pm SD), Yuan & & \\
Per capita housing area & $25.6 \pm 6.4$ & $25.6 \pm 6.5$ \\
$\quad$ (mean \pm SD), m & \\
Medical staff, $n$ & & \\
Doctors, $n$ (\%) & 2,162 & 2,147 \\
Nurses, $n$ (\%) & $654(38.1)$ & $648(37.0)$ \\
Medical staff educational & $1,041(38.7)$ & $1,058(41.0)$ \\
$\quad$ background, $n$ & & \\
$\quad$ Undergraduate or above & & 1,573 \\
$\quad$ Junior college & 1,576 & 479 \\
Medical staff professional & 482 & \\
$\quad$ title, $n$ & & 555 \\
$\quad$ Senior & & \\
Intermediate & 559 & 878 \\
\hline
\end{tabular}

ing from 0 to 10 points, with a higher score indicating greater severity.

Secondary outcome measures were changes in COPD knowledge, awareness, and risk factors, which were measured with a survey that included questions on epidemiology, prevention, treatment, and rehabilitation. The questionnaire consisted of 100 items (each item assigned one score) designed by us. Cumulative COPD deaths for all causes within 96 months were entered through our link to the China Information System for Disease Control and
Prevention, and the authors verified the information for each deceased subject. Changes in anxiety and depression symptoms were measured with the Hospital Anxiety and Depression Scale (HADS), ${ }^{16}$ in which higher scores indicate a greater likelihood of anxiety or depression. Changes in hospital admissions and emergency department visits, as well as changes in medication regimens, were obtained by subject interview, health-care databases, or prospectively from diary cards, and frequency was recorded.

\section{Statistical Analysis}

SPSS 13.0 (SPSS, Chicago, Illinois) was used for all calculations. Descriptive statistics were performed for all recorded variables. Baseline characteristics between the 2 groups were compared using the unpaired $t$ test for age, income, BODE index, 6-min walk distance (6MWD), MMRC scores, BMI, and $\mathrm{FEV}_{1}$ (\% predicted), whereas the chi-square test was used for analysis of sex, education, marriage, smoking, passive smoking, exposure to coal and/or biomass smoke history, comorbidity, HADS-anxiety, and HADS-depression. For the BODE index and its components, we compared the estimated mean cumulative functions between disease management and usual care. Results are presented as change between post-intervention and baseline levels ( $\Delta$ values). We also used a generalized linear model with a log link and negative binomial random component to compare the rate of hospital admissions and emergency department visits. A general or generalized linear regression function was employed to compare changes in COPD knowledge, risk factors for COPD, anxiety and

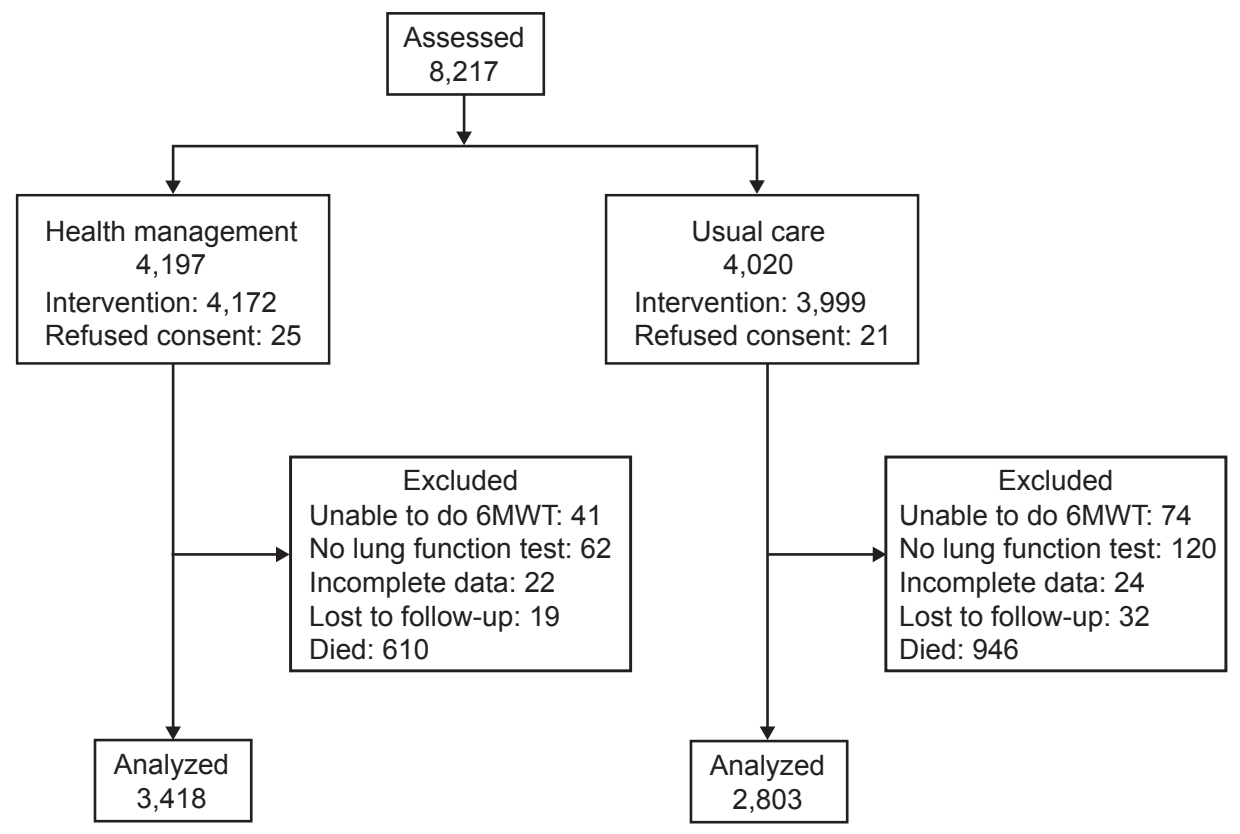

Fig. 1. Trial profile. $6 \mathrm{MWT}=6$-min walk test. 
depression symptoms, all-cause mortality rates, total days hospitalized, total days in the emergency department, and the number of out-patient respiratory medication prescriptions. The threshold for statistical significance was set at $P=.05$.

\section{Results}

\section{Frequency of Health Service Received by Subjects}

The 2 groups were drawn from a single district and were similar at baseline in terms of annual average income, access to health services, and main demographic characteristics (Table 1). Figure 1 shows the progress of subjects through the study. According to the requirements of our study, all subjects with COPD participated in the activities provided by the caregivers. In total, the subjects received a mean \pm SD of $96 \pm 12.6$ follow-ups by caregivers. The greatest number of follow-ups was 112, which accounted for $85.2 \%(3,576 / 4,197)$ of the study population, whereas 71 was the least number of follow-ups, accounting for $4.5 \%(189 / 4,197)$ of all subjects. In our study, $86.7 \%$ of subjects attended the 48 COPD health education lectures. The participation rates for mandated daily breathing exercise training, abdominal respiration, breathing exercises, and limb training were $95.6 \%, 94.3 \%, 94.1 \%$, and $91.5 \%$, respectively. Although $100 \%$ of subjects reported that they paid attention to their everyday diet, only $47 \%$ of subjects insisted on eating 3 meals/d as dictated by the requirements of the dietary guidelines.

\section{General Characteristics of Subjects at Baseline Survey and at 4-y Follow-Up}

The 8,217 subjects who fulfilled the study criteria were placed into the management or control groups. No health

Table 2. Baseline Characteristics of Subjects Randomly Selected From 2 Communities

\begin{tabular}{|c|c|c|c|}
\hline Variable & Management Group & Control Group & $P$ \\
\hline Subjects, $n$ & 4,197 & 4,020 & \\
\hline Males, $n(\%)$ & $2,006(47.8)$ & $1,924(47.9)$ & .95 \\
\hline Age $($ mean $\pm S D), y$ & $61.6 \pm 13.5$ & $61.4 \pm 13.2$ & .50 \\
\hline Educational levels (high school and above), $n(\%)$ & $378(9.0)$ & $345(8.6)$ & .50 \\
\hline Married, $n(\%)$ & $3,025(72.1)$ & $2,865(71.3)$ & .42 \\
\hline Annual per capita income (mean \pm SD), Yuan & $6,820 \pm 280$ & $6,830 \pm 290$ & .11 \\
\hline Smokers, $n(\%)$ & $1,895(45.2)$ & $1,797(44.7)$ & .68 \\
\hline Smoking history of $>10$ pack-years, $n(\%)$ & $1,814(43.2)$ & $1,748(43.5)$ & .81 \\
\hline Passive smoking, $n(\%)$ & $642(15.3)$ & $631(15.7)$ & .62 \\
\hline Exposure to coal and/or biomass smoke, $n(\%)$ & $1,624(38.7)$ & $1,532(38.1)$ & .59 \\
\hline Exposure to biomass smoke in non-smokers, $n(\%)$ & $1,395(33.2)$ & $1,307(32.5)$ & .48 \\
\hline Comorbidity, $n(\%)$ & $1,280(30.5)$ & $1,198(29.8)$ & .49 \\
\hline Immunomodulator, $n(\%)$ & $734(17.5)$ & $719(17.9)$ & .59 \\
\hline Hospitalized for COPD in the past year, $n(\%)$ & $1,519(36.2)$ & $1,443(35.9)$ & .78 \\
\hline Emergency department visit for COPD in the past year, $n(\%)$ & $2,413(57.5)$ & $2,263(56.3)$ & .27 \\
\hline HADS-anxiety $\geq 8, n(\%)$ & $768(18.3)$ & $732(18.2)$ & .92 \\
\hline HADS-depression $\geq 8, n(\%)$ & $1,477(35.2)$ & $1,403(34.9)$ & .78 \\
\hline BODE index, median (IQR)* & $4(1-6)$ & $4(1-6)$ & $>.99$ \\
\hline 6MWD, median (IQR), m* & $367(307-392)$ & $366(305-390)$ & .45 \\
\hline MMRC, median (IQR) & $2(0-4)$ & $2(0-4)$ & $>.99$ \\
\hline BMI, median (IQR), $\mathrm{kg} / \mathrm{m}^{2 *}$ & $23.0(20.1-24.3)$ & $22.9(20.0-24.4)$ & .84 \\
\hline $\mathrm{FEV}_{1}$, median (IQR), \% predicted* & $55.1(82.1-45.3)$ & $55.5(8.8-44.6)$ & .42 \\
\hline Awareness scores (mean $\pm \mathrm{SD})$ & $15.3 \pm 4.2$ & $15.6 \pm 4.1$ & $<.001$ \\
\hline \multicolumn{4}{|l|}{ Respiratory medication, $n(\%)$} \\
\hline Long-acting $\beta$ agonists & $0(0)$ & $0(0)$ & \\
\hline Inhaled corticosteroids & $437(10.4)$ & $411(10.2)$ & .86 \\
\hline Chronic systemic corticosteroids & 815 (19.4) & 788 (19.6) & .85 \\
\hline Theophylline & $1,418(33.8)$ & $1,371(34.1)$ & .68 \\
\hline $\begin{array}{l}\text { * Nonparametric inferential statistics } \\
\text { HADS = Hospital Anxiety and Depression Scale } \\
\text { IQR }=\text { interquartile range } \\
\text { 6MWD }=6 \text {-min walk distance } \\
\text { MMRC = Modified Medical Research Council } \\
\text { BMI = body mass index }\end{array}$ & & & \\
\hline
\end{tabular}


Table 3. Characteristics of Subjects Who Dropped Out

\begin{tabular}{|c|c|c|c|}
\hline Parameter & $\begin{array}{c}\text { Management } \\
\text { Group } \\
(n=769)\end{array}$ & $\begin{array}{c}\text { Control } \\
\text { Group } \\
(n=1,217)\end{array}$ & \\
\hline Males, $n(\%)$ & $574(74.6)$ & $905(74.4)$ & .89 \\
\hline Age (mean $\pm \mathrm{SD}), \mathrm{y}$ & $71.2 \pm 7.4$ & $71.5 \pm 7.8$ & .40 \\
\hline $\begin{array}{l}\text { Education level (high school } \\
\text { or above), } n(\%)\end{array}$ & $6(0.8)$ & $9(0.7)$ & .92 \\
\hline Married, $n(\%)$ & $189(24.6)$ & $307(25.2)$ & .74 \\
\hline $\begin{array}{l}\text { Annual per capita income } \\
\quad(\text { mean } \pm \text { SD }) \text {, Yuan }\end{array}$ & $5,320 \pm 310$ & $5,350 \pm 320$ & .04 \\
\hline BMI (mean $\pm \mathrm{SD}), \mathrm{kg} / \mathrm{m}^{2}$ & $21.3 \pm 2.5$ & $21.1 \pm 2.7$ & .10 \\
\hline Smoking, $n(\%)$ & $630(81.9)$ & $1010(83.0)$ & .54 \\
\hline Passive smoking, $n(\%)$ & $122(15.9)$ & $196(16.1)$ & .89 \\
\hline $\begin{array}{l}\text { Exposure to coal and/or } \\
\text { biomass smoke, } n(\%)\end{array}$ & $315(41.0)$ & $481(39.5)$ & .52 \\
\hline Comorbid diseases, $n(\%)$ & $354(46.0)$ & $578(47.5)$ & .53 \\
\hline BODE index $($ mean $\pm \mathrm{SD})$ & $5.8 \pm 1.4$ & $5.9 \pm 1.5$ & .14 \\
\hline HADS-anxiety $\geq 8, n(\%)$ & $235(30.6)$ & $403(33.1)$ & .24 \\
\hline HADS-depression $\geq 8, n(\%)$ & $317(41.2)$ & $537(44.1)$ & .20 \\
\hline \multicolumn{4}{|c|}{$\begin{array}{l}\text { There was no significant difference }(P>.05) \text { between comparable groups }(Z \text { test or chi-square } \\
\text { test). } \\
\text { BMI = body mass index } \\
\text { HADS = Hospital Anxiety and Depression Scale }\end{array}$} \\
\hline
\end{tabular}

centers had previous experience with health management counseling. After 4 y, 75.7\% $(6,221 / 8,217)$ of recruited subjects completed the final analysis (see Fig. 1). Reasons for dropping out after randomization were refusal to continue participation (25 subjects in the management group and 21 in the control group), lost to follow-up (19 subjects in the management group and 32 in the control group), and death (610 subjects in the management group and 946 in the control group). Subjects were excluded from analysis because of inability to perform the 6MWT (41 subjects in the management group and 74 in the control group), incomplete lung function testing (62 subjects in the management group and 120 in the control group), and incomplete data (22 subjects in the management group and 24 in

Table 4. Reasons Given by Subjects Who Dropped Out

\begin{tabular}{lccc}
\hline \hline \multicolumn{1}{c}{ Variable } & $\begin{array}{c}\text { Management } \\
\text { Group } \\
(n=4,197)\end{array}$ & $\begin{array}{c}\text { Control } \\
\text { Group } \\
(n=4,020)\end{array}$ & $P$ \\
\hline Death, $n(\%)$ & $610(14.5)$ & $946(23.5)$ & $<.001$ \\
Unable to contact, $n(\%)$ & $19(0.5)$ & $32(0.8)$ & .05 \\
Inability to perform 6MWT, $n(\%)$ & $41(1.0)$ & $74(1.8)$ & $<.001$ \\
Incomplete lung function test, $n(\%)$ & $62(1.5)$ & $120(3.0)$ & $<.001$ \\
Refused to participate, $n(\%)$ & $25(0.6)$ & $21(0.5)$ & .66 \\
Incomplete data, $n(\%)$ & $22(0.5)$ & $24(0.6)$ & .66 \\
Total, $n(\%)$ & $779(18.6)$ & $1,217(30.3)<.001$
\end{tabular}

$\overline{6 \mathrm{MWT}=6-\mathrm{min} \text { walk }}$ test
Table 5. Difference Between 2 Groups Regarding Changes in BODE Index, 6MWD, MMRC, BMI, and Percent-ofPredicted $\mathrm{FEV}_{1}$

\begin{tabular}{|c|c|c|c|c|}
\hline \multirow{2}{*}{ Parameter } & \multirow{2}{*}{$\begin{array}{c}\text { Management } \\
\text { Group } \\
\text { (Mean } \pm \mathrm{SD})\end{array}$} & \multirow{2}{*}{$\begin{array}{c}\text { Control } \\
\text { Group } \\
(\text { Mean } \pm \mathrm{SD})\end{array}$} & \multicolumn{2}{|c|}{ Adjusted Difference* } \\
\hline & & & $\begin{array}{l}\text { Median } \\
(95 \% \text { CI })\end{array}$ & $P$ \\
\hline$\triangle \mathrm{BODE}$ index & $0.4 \pm 0.3$ & $-0.7 \pm 0.5$ & $1.1(0.2-2.0)$ & $<.001$ \\
\hline$\Delta 6 \mathrm{MWD}, \mathrm{m}$ & $16 \pm 7$ & $-27 \pm 12$ & $43(12-75)$ & $<.001$ \\
\hline$\Delta \mathrm{MMRC}$ & $0.4 \pm 0.3$ & $-0.3 \pm 0.2$ & $0.7(0.2-0.9)$ & $<.001$ \\
\hline$\Delta \mathrm{BMI}, \mathrm{kg} / \mathrm{m}^{2}$ & $0.5 \pm 0.4$ & $-0.5 \pm 0.3$ & $1.0(0.3-1.9)$ & $<.001$ \\
\hline $\begin{array}{l}\Delta \mathrm{FEV}_{1}, \\
\quad \% \text { predicted }\end{array}$ & $-5.9 \pm 3.2$ & $-6.5 \pm 2.9$ & $0.6(0.2-1.1)$ & .01 \\
\hline
\end{tabular}

* Values were adjusted for baseline BODE index, age, sex, education, annual per capita income, smoking status, comorbidity, HADS-anxiety, HADS-depression, 6-min walk distance (6MWD), Modified Medical Research Council (MMRC), body mass index (BMI), exposure to coal and/or biomass smoke, and clustering effects.

the control group). Demographic characteristics of the subjects, including the 4,197 subjects in the management group and the 4,020 subjects in the control group, are summarized in Table 2. There were no significant differences between the 2 groups at baseline. Notably, of the 8,217 subjects who were initially enrolled in the study, 1,996 (24.3\%) failed to complete the study, including $779(18.6 \%)$ from the management group and 1,217 (30.3\%) from the control group. There was a significant difference in the dropout rate between the 2 groups $(P<.05)$. The general characteristics of those who did not complete the study were not significantly different between the management and control groups (all $P>.05$ ), as shown in Table 3. In both groups, compared with the subjects who completed the study, those who failed to complete the study were older, less educated, less likely to be married, more likely to be smokers, and more likely to be associated with coal and/or biomass smoke exposure and had lower incomes, lower BMI, and higher comorbidity rates (all $P<.001$ ) (Table 3). In summary, there were no significant differences in the baseline characteristics between the 2 groups. However, the rates of failure for the 6MWT and lung function tests were significantly higher in the control group at the end of the study (Table 4). For the 6,221 analyzed subjects, no significant differences were observed between the 2 groups (all $P>.05$ ).

\section{BODE Index}

After the 4-y intervention, the BODE index in the health management group decreased by $0.4 \pm 0.3$ (mean $\pm \mathrm{SD}$ ), whereas there was an increase of $0.7 \pm 0.5$ in the control group. This difference was statistically significant (difference of $1.1,95 \%$ CI $0.2-2.0, P<.001$ ) (Table 5). The BODE index scores of all subgroups were increased in the 
Table 6. Variation of the BODE Index and Its Components in Subgroups of Subjects With COPD

\begin{tabular}{|c|c|c|c|c|c|c|c|c|}
\hline \multirow[b]{2}{*}{ Parameter } & \multicolumn{2}{|c|}{ Grade I (Mean \pm SD) } & \multicolumn{2}{|c|}{ Grade $\Pi($ Mean \pm SD $)$} & \multicolumn{2}{|c|}{ Grade II (Mean \pm SD) } & \multicolumn{2}{|c|}{ Grade IV $($ Mean \pm SD) } \\
\hline & $\begin{array}{l}\text { Management } \\
\text { Group } \\
(n=513)\end{array}$ & $\begin{array}{l}\text { Control } \\
\text { Group } \\
(n=413)\end{array}$ & $\begin{array}{l}\text { Management } \\
\text { Group } \\
(n=1,428)\end{array}$ & $\begin{array}{l}\text { Control } \\
\text { Group } \\
(n=1,165)\end{array}$ & $\begin{array}{l}\text { Management } \\
\text { Group } \\
(n=901)\end{array}$ & $\begin{array}{c}\text { Control } \\
\text { Group } \\
(n=736)\end{array}$ & $\begin{array}{l}\text { Management } \\
\text { Group } \\
(n=586)\end{array}$ & $\begin{array}{c}\text { Control } \\
\text { Group } \\
(n=489)\end{array}$ \\
\hline$\triangle \mathrm{BODE}$ index & $0.0 \pm 0.1$ & $-0.1 \pm 0.1$ & $0.4 \pm 0.3$ & $-0.4 \pm 0.4$ & $0.3 \pm 0.2$ & $-0.9 \pm 0.5$ & $0.6 \pm 0.4$ & $-1.2 \pm 0.6$ \\
\hline$\Delta 6 \mathrm{MWD}(\mathrm{m})$ & $9 \pm 3$ & $-21 \pm 8$ & $14 \pm 5$ & $-25 \pm 11$ & $16 \pm 8$ & $-29 \pm 13$ & $21 \pm 10$ & $-33 \pm 15$ \\
\hline$\Delta \mathrm{MMRC}$ & $0.0 \pm 0.1$ & $-0.1 \pm 0.1$ & $0.3 \pm 0.2$ & $-0.2 \pm 0.1$ & $0.7 \pm 0.3$ & $-0.4 \pm 0.3$ & $0.8 \pm 0.5$ & $-0.5 \pm 0.4$ \\
\hline$\Delta \mathrm{BMI}, \mathrm{kg} / \mathrm{m}^{2}$ & $0.3 \pm 0.3$ & $-0.2 \pm 0.2$ & $0.5 \pm 0.4$ & $-0.3 \pm 0.2$ & $0.5 \pm 0.5$ & $-0.5 \pm 0.4$ & $0.5 \pm 0.4$ & $-0.7 \pm 0.5$ \\
\hline$\Delta \mathrm{FEV}_{1}, \%$ predicted & $-1.7 \pm 0.6$ & $-2.7 \pm 0.7$ & $-4.6 \pm 2.6$ & $-5.1 \pm 2.5$ & $-5.9 \pm 4.8$ & $-7.0 \pm 3.4$ & $-2.3 \pm 2.1$ & $-2.4 \pm 2.3$ \\
\hline \multicolumn{9}{|c|}{$\begin{array}{l}P \text { values are all }<.01 \\
6 \text { MWD }=6 \text {-min walk distance } \\
\text { MMRC }=\text { Modified Medical Research Council } \\
\text { BMI = body mass index }\end{array}$} \\
\hline
\end{tabular}

control group; however, in the health management group, these scores were decreased in all subgroups except for the grade I subgroup (Table 6).

\section{Exercise Capacity}

After $4 \mathrm{y}$, the 6MWD in the management group increased by $16 \pm 7 \mathrm{~m}$ (mean $\pm \mathrm{SD}$ ), whereas the 6MWD in the control group decreased by $27 \pm 12 \mathrm{~m}$. This difference was statistically significant (difference of $43 \mathrm{~m}$, 95\% CI 12-75, $P<.001$ ) (see Table 5). The 6MWD increased significantly in all management subgroups with the exception of the grade I subgroup; in contrast, the 6MWD decreased significantly in all control subgroups (see Table 6).

\section{Dyspnea}

After $4 \mathrm{y}$, the mean MMRC score in the management group decreased by $0.4 \pm 0.3$ (mean $\pm \mathrm{SD}$ ), whereas in the control group, this score increased by $0.3 \pm 0.2$. There was a significant difference between the 2 groups (difference of $0.6,95 \%$ CI $0.2-0.9, P<.001$ ). The MMRC scores increased significantly in all subgroups of the control group, but decreased significantly in subgroups of the health management group (see Table 6).

\section{BMI}

At the 4-y follow-up, the BMI in the management group increased by $0.5 \pm 0.4$ (mean $\pm \mathrm{SD}$ ), in contrast to a

Table 7. Secondary Outcomes During Follow-Up

\begin{tabular}{|c|c|c|c|c|}
\hline Variable & $\begin{array}{l}\text { Management Group } \\
\quad(n=3,418)\end{array}$ & $\begin{array}{l}\text { Control Group } \\
\quad(n=2,803)\end{array}$ & $\begin{array}{l}\text { Difference } \\
(95 \% \mathrm{CI})\end{array}$ & $P$ \\
\hline Awareness scores, $\pm \mathrm{SD}$ & 73.4 & 16.5 & $57.2(35.3-70.2)$ & $<.001$ \\
\hline Death rate, $\%$ & 14.5 & 23.5 & $9.0(5.6-12.7)$ & $<.001$ \\
\hline Current smoker, $\%$ & 27.3 & 41.6 & $14.3(8.5-20.7)$ & $<.001$ \\
\hline Exposure to coal and/or biomass smoke, $\%$ & 24.2 & 38.2 & $14.0(7.6-19.8)$ & $<.001$ \\
\hline HADS-anxiety $\geq 8, \%$ & 15.2 & 20.0 & $4.9(2.1-8.2)$ & .01 \\
\hline HADS-depression $\geq 8, \%$ & 31.4 & 38.0 & $6.9(3.2-10.9)$ & $<.001$ \\
\hline Immunomodulators, $\% *$ & 77.1 & 18.6 & $58.9(35.6-72.5)$ & $<.001$ \\
\hline Hospitalizations, $\%$ & 20.1 & 36.2 & $16.1(9.3-23.2)$ & $<.001$ \\
\hline Emergency department visits, $\%$ & 38.3 & 56.4 & $18.1(10.2-27.9)$ & $<.001$ \\
\hline \multicolumn{5}{|l|}{ Respiratory medication, $\%$} \\
\hline Long-acting $\beta$ agonists & 16.4 & 2.3 & $14.1(8.4-20.3)$ & $<.001$ \\
\hline Inhaled corticosteroids & 32.5 & 10.6 & $21.9(11.6-33.7)$ & $<.001$ \\
\hline Chronic systemic corticosteroids & 40.7 & 20.7 & $20.0(9.5-31.2)$ & $<.001$ \\
\hline Theophylline & 45.0 & 34.8 & $10.2(4.7-17.4)$ & $<.001$ \\
\hline
\end{tabular}

* Immunomodulators includes influenza vaccine, pneumonia vaccine, bronchitis vaccine, immunoglobulin, etc. HADS $=$ Hospital Anxiety and Depression Scale 
decrease of $0.5 \pm 0.3$ in the control group. This difference was statistically significant (difference of $1.0,95 \%$ CI $0.3-$ $1.9, P<.001$ ) (see Table 5). The BMI increased significantly in all subgroups of the health management group, whereas the scores decreased significantly in all subgroups of the control group (see Table 6).

\section{Lung Function}

After $4 \mathrm{y}$, there was a significant difference between the 2 groups (difference of $0.6,95 \%$ CI $0.2-1.1, P=.01$ ) (see Table 5). The total or subgroup $\mathrm{FEV}_{1}$, with the exception of the grade IV subgroup, was significantly reduced in the 2 groups $(P<.001)$. However, a smaller reduction in $\mathrm{FEV}_{1}$ was observed in the grade I, II, and III subgroups of the management group compared with the control group (grade I, $P<.001$; grade II, $P<.001$; grade III, $P<.001$ ) (see Table 6).

\section{Changes in Anxiety and Depression Rates}

After $4 \mathrm{y}$ of health management, the rate of anxiety in the management group decreased by $3.1 \%$, but increased by $1.8 \%$ in the control group. The difference in the end point scores between the management and control groups was statistically significant (difference of $4.9 \%, 95 \%$ CI $2.1-8.2, P<.001$ ). The rate of depression in the management group decreased by $3.8 \%$ at the $4-y$ follow-up; in contrast, this rate increased by $3.1 \%$ in the control group. This difference was statistically significant (difference of $6.9 \%, 95 \%$ CI 3.2-10.9, $P<.001$ ) (Table 7).

\section{Changes in Other Risk Factors for COPD}

After $4 \mathrm{y}$, the COPD awareness score in the management group increased by 58.1, compared with a 0.9 increase in the control group (difference of $57.2,95 \% \mathrm{CI}$ 35.3-70.2, $P<.001$ ). Moreover, compared with subjects in the control group, more subjects in the management group reported influenza or pneumococcal vaccinations ( $77.1 \%$ vs $18.6 \%$ ), reduced hospitalizations (20.1 vs 36.2 ), and reduced emergency department visits (38.3 vs 56.4 ) (see Table 7). The percentage of current smokers in the health management group was $27.3 \%$, which was lower than the $41.6 \%$ observed in the control group (difference of $14.3,95 \%$ CI $8.5-20.7, P<.001)$. The percentage of subjects with current exposure to coal and/or biomass smoke in the management group was $24.3 \%$, which was also lower than the rate in the control group (38.2\%). The cumulative death rate for all causes was significantly lower in the management group $(14.5 \%, 610 / 4,197)$ than in the control group $(23.5 \%, 946 / 4,020)$ (difference of $9.0,95 \% \mathrm{CI}$ 5.6-12.7, $P<.001)$.

\section{Changes in Medication Regimens}

After $4 \mathrm{y}$, the frequency of medication use in the management group increased from 0 to $16.4 \%, 10.4$ to $32.5 \%$, 19.4 to $40.7 \%$, and 33.8 to $45.0 \%$ (all $P<.001$ ) for long-acting $\beta$ agonists, inhaled corticosteroids, chronic systemic corticosteroids, and theophylline, respectively, compared with increases from 0 to $2.3 \%, 10.2$ to $10.6 \%, 19.6$ to $20.7 \%$, and 34.1 to $34.8 \%(P>.05)$ in the control group. Therefore, the frequency of medication use in the management group was significantly higher than that in the control group (all $P<.001$ ) (see Table 7).

\section{Discussion}

In this study, we developed an out-patient-based health management program and tested its potential as a reliable and effective community-based intervention strategy for the prevention and management of COPD in rural areas of China. Our results showed that this 4-y health management program exerted a positive impact on the subjects' condition and health status, as evidenced by the decrease in the BODE index, HADS-anxiety and HADS-depression rates, cumulative death rate, current smoking rate, and number of hospitalizations and emergency department visits. There was also an improvement in behavioral risk factor and COPD awareness and in respiratory medication use.

Previous studies of multiple COPD risk factors, lung health, and community-based intervention focused on changes in $\mathrm{FEV}_{1} \cdot{ }^{17-20} \mathrm{~A}$ few studies on the respiratory and systemic manifestations of COPD showed that the FEV ${ }_{1}$, expressed as the percentage of predicted values, did not change significantly in subjects with $\mathrm{COPD}, 21,22$ which is consistent with our findings. Our results show that the decrease in $\mathrm{FEV}_{1}$ in subjects with stage I and II COPD in the health management group was less pronounced than that in the control group. However, the impact of COPD on subjects depends mostly on the severity of the symptoms, rather than just the degree of air-flow limitation. 21,23-25 Therefore, the $\mathrm{FEV}_{1}$ alone is not sufficient to provide an accurate evaluation of the efficacy of a COPD management intervention program. In this study, the efficacy of a community-based intervention program that we developed was assessed regarding multiple aspects of COPD management. We observed a less pronounced decrease in the BODE index, as well as lower anxiety and depression rates, in the management group compared with the control group.

Although the BODE score of subjects with stage I COPD was not significantly improved in the management group, the health management program could prevent it from declining. In addition, improvements in other parameters, such as risk factors and anxiety and depression symptoms, 
indicate that a health management program implemented early should be beneficial in preventing disease progression in patients with COPD.

Smoking is one of the most important causes of chronic respiratory diseases, including COPD. ${ }^{26,27}$ Smoking cessation is the only approach that can effectively slow the progression of COPD and mitigate its clinical course. ${ }^{26,28}$ It can delay the impairment of pulmonary function and significantly alleviate the symptoms of coughing, excess phlegm, and asthma, thereby improving patient health status. ${ }^{29-31}$ Long-term smoking cessation has been found to improve the natural course of COPD and to mitigate the deterioration of lung function in patients with COPD. ${ }^{32}$ Thus, we included smoking cessation as a key component of our program. After the 4-y health management program, smoking rates decreased markedly.

Exposure to coal and/or biomass smoke is a major risk factor for developing COPD in non-smokers in China. ${ }^{33}$ People exposed to biomass smoke have an odds ratio of 2.44 (95\% CI 1.9-3.3) for developing COPD relative to those not exposed to biomass smoke. ${ }^{34}$ In our study, $38.7 \%$ of subjects were exposed to biomass smoke. Among nonsmokers, $67.5 \%(1,395 / 2,067)$ of subjects were exposed to biomass smoke. After a 4-y health management program, the rate of exposure to coal and/or biomass smoke was reduced by $14.0 \%$ in the management group compared with the control group. This result shows that the health management program was effective in reducing exposure to biomass smoke.

The longer patients suffer from COPD, the more likely they are to feel lonely, fearful, anxious, and depressed. ${ }^{35,36}$ Systematic education and strict management can improve their confidence and increase their awareness of COPD. Previous studies have shown that both a one-time intensive 2-h session of cognitive behavioral therapy and an 8 -week intervention significantly relieved the symptoms of depression and anxiety. This improvement was markedly greater than that achieved with education alone. ${ }^{37-39}$ Therefore, both health education and psychological counseling were included in our program. COPD awareness was increased and anxiety and depression rates were decreased significantly at the end of our study.

Influenza and pneumococcal vaccinations are recommended as part of a COPD risk reduction strategy. ${ }^{23} \mathrm{In}$ particular, influenza vaccination has been shown to prevent acute respiratory infections in patients with different stages of COPD. ${ }^{40}$ Therefore, in our intervention program, subjects were instructed to obtain influenza and pneumococcal vaccinations along with immunomodulatory agents, which may improve a subject's immune system.

$\mathrm{Yu}$ et $\mathrm{al}^{41}$ reported that patients with COPD are more likely to have a poor educational background and receive insufficient treatment. Disease management for these patients can be accomplished by increasing their accessibil- ity to structured education programs and long-acting bronchodilator drug use. Although our health management program did not include long-acting bronchodilator drugs, it did provide targeted measures, including smoking cessation, psychological counseling, and a pulmonary rehabilitation program. Therefore, it improved the health status of subjects with COPD. Our findings suggest that this health management program could be applied to patients with COPD in a community setting.

The death rates and hospitalizations in the control group were higher than those in the management group, which cannot be fully credited to the effects of health management and may be attributed to use of more medications. In contrast, the results indicate that practitioners need more drugs to treat COPD and that patients with COPD need more regular treatments.

In addition, the rates of failure in the 6MWD and lung function tests were higher in the control group than in the health management group at the end of the study, which may result in an underestimation of the efficacy of the health management program. The rate of death in the control group was higher than that in the management group. A decreased death rate was one of our intervention goals, but it may amplify the effects of health management.

The strengths of this study include the community-based intervention design, large sample size, randomly selected management and control groups, and low rate of loss to follow-up. Ascertainment of outcomes was complete. An extensive list of physical symptoms, disorders, and behavior risk factors was assessed to identify changes during the intervention period in this sample.

\section{Limitations of the Study}

Some limitations of our study should be mentioned. First, all study subjects in the intervention and control groups were from 14 rural communities in and around Xuzhou City, China; therefore, this sampling strategy may limit the applicability of these findings to other regions and other countries. Second, this approach of specifically targeting rural areas within a specific geographic region is of particular value for the practical design of a community-based COPD health management system, but the results cannot be fully reproduced in other scenarios. Third, more medication for the intervention group was one of our intervention goals, but it may amplify the effects of health management. Fourth, the high death rate in the control group may also be expanded to the effects of health management in the intervention group. The number of hospitalizations in the intervention group was less than that in the control group, which may be the result of health management or the use of more medications in the intervention group. 


\section{Conclusions}

Despite the above limitations, we believe that our results have significance for public health. The health management program significantly increased awareness and knowledge among patients and practitioners, improved management within the limitations of access to pharmacotherapy, and reduced the rates of HADS and smoking, indirectly manifesting the changes in the BODE index. These finding support the idea that our health management program may serve as an effective intervention strategy for managing patients with COPD who reside in rural areas. Given the irregularity of treating patients with COPD in rural areas of China, use of the health management approach would be an inexpensive and practical means of increasing awareness and knowledge among patients and practitioners, improving management within the limitations of access to pharmacotherapy, and reducing psychological disorders and smoking, indirectly preventing deterioration and decreasing deaths from COPD.

Considering the practical setting in China, the most useful and essential measures are those that include providing health lectures, teaching inhaler techniques, smoking cessation counseling, recommendations concerning influenza and pneumococcal vaccinations, and encouragement of regular exercise in improving health status of patients with COPD.

\section{REFERENCES}

1. Fabbri LM, Rabe KF. From COPD to chronic systemic inflammatory syndrome? Lancet 2007;370(9589):797-799.

2. Bailey WC, Tashkin DP. Pharmacologic therapy: novel approaches for chronic obstructive pulmonary disease. Proc Am Thorac Soc 2007;4(7):543-548

3. Nussbaumer-Ochsner Y, Rabe KF. Systemic manifestations of COPD. Chest 2011;139(1):165-173.

4. Lacasse Y, Martin S, Lasserson TJ, Goldstein RS. Meta-analysis of respiratory rehabilitation in chronic obstructive pulmonary disease. A Cochrane systematic review. Eura Medicophys 2007;43(4):475485.

5. van Wetering CR, Hoogendoorn M, Mol SJ, Rutten-van Mölken MP, Schols AM. Short- and long-term efficacy of a community-based COPD management programme in less advanced COPD: a randomised controlled trial. Thorax 2010;65(1):7-13.

6. Bodenheimer T, Wagner EH, Grumbach K. Improving primary care for patients with chronic illness: the chronic care model, Part 2. JAMA 2002;288(15):1909-1914.

7. Ries AL, Bauldoff GS, Carlin BW, Casaburi R, Emery CF, Mahler DA, et al. Pulmonary rehabilitation: joint ACCP/AACVPR evidencebased clinical practice guidelines. Chest 2007;131(5 Suppl):4S-42S.

8. Ergün P, Kaymaz D, Günay E, Erdoğan Y, Turay UY, Demir N, et al. Comprehensive outpatient pulmonary rehabilitation: treatment outcomes in early and late stages of chronic obstructive pulmonary disease. Ann Thorac Med 2011;6(2):70-76

9. Rice KL, Dewan N, Bloomfield HE, Grill J, Schult TM, Nelson DB, et al. Disease management program for chronic obstructive pulmonary disease: a randomized controlled trial. Am J Respir Crit Care Med 2010;182(7):890-896.
10. Tsui EW, Wang G, Zahler A, Simoyan OM, White MV, Mckee M. A multilingual population health management program. J Ambul Care Manage 2013;36(2):140-146.

11. Lou P, Zhu Y, Chen P, Zhang P, Yu J, Zhang N, et al. Vulnerability, beliefs, treatments and economic burden of chronic obstructive pulmonary disease in rural areas in China: a cross-sectional study. BMC Public Health 2012;12:287.

12. Global Initiative for Chronic Obstructive Pulmonary Disease. Global strategy for the diagnosis, management, and prevention of chronic obstructive pulmonary disease. 2011. http://www.goldcopd.org/up loads/users/files/GOLD_Report_2011_Jan21.pdf. Accessed September 18, 2014.

13. Celli BR, Cote CG, Marin JM, Casanova C, Montes de Oca M, Mendez RA, et al. The body mass index, airflow obstruction, dyspnea, and exercise capacity index in chronic obstructive pulmonary disease. N Engl J Med 2004;350(10):1005-1012.

14. ATS Committee on Proficiency Standards for Clinical Pulmonary Function Laboratories. ATS statement: guidelines for the six-minute walk test. Am J Respir Crit Care Med 2002;166(1):111-117.

15. Bestall JC, Paul EA, Garrod R, Garnham R, Jones PW, Wedzicha JA. Usefulness of the Medical Research Council (MRC) dyspnoea scale as a measure of disability in patients with chronic obstructive pulmonary disease. Thorax 1999;54(7):581-586.

16. Bjelland I, Dahl AA, Haug TT, Neckelmann D. The validity of the Hospital Anxiety and Depression Scale: an updated literature review. J Psychosom Res 2002;52(2):69-77.

17. van Wetering CR, Hoogendoorn M, Broekhuizen R, Geraerts-Keeris GJ, De Munck DR, Rutten-van Mölken MP, Schols AM. Effective and costs of nutritional rehabilitation in muscle-waste patients with chronic obstructive pulmonary disease in community-based setting: a prespecified subgroup analysis of the INTERCOM trail. J Am Med Dir Assoc 2010;11(3):179-187.

18. Zhou Y, Hu G, Wang D, Wang S, Wang Y, Liu Z, et al. Communitybased integrated intervention for prevention and management of chronic obstructive pulmonary disease (COPD) in Guangdong, China: cluster randomised controlled trial. BMJ 2010;341:c6387.

19. Browner WS, Du Chene AG, Hulley SB. Effects of the Multiple Risk Factor Intervention Trial smoking cessation program on pulmonary function-a randomized controlled trial. West J Med 1992;157(5): 534-538.

20. Anthonisen NR, Connett JE, Kiley JP, Altose MD, Bailey WC, Buist AS, et al. Effects of smoking intervention and the use of an inhaled anticholinergic bronchodilator on the rate of decline of $\mathrm{FEV}_{1}$ the lung health study. JAMA 1994;272(19):1497-1505.

21. Ferrari R, Tanni SE, Faganello MM, Caram LM, Lucheta PA, Godoy I. Three-year follow-up study of respiratory and systemic manifestations of chronic obstructive pulmonary disease. Braz J Med Biol Res 2011;44(1):46-52.

22. Casanova C, Cote CG, Marin JM, de Torres JP, Aguirre-Jaime A, Mendez R, et al. The 6-min walking distance: long-term follow up in patients with COPD. Eur Respir J 2007;29(3):535-540.

23. Pauwels RA, Rabe KF. Burden and clinical features of chronic obstructive pulmonary disease (COPD). Lancet 2004;364(9434):613620.

24. Rennard S, Decramer M, Calverley PM, Pride NB, Soriano JB, Vermeire PA, Vestbo J. Impact of COPD in North America and Europe in 2000: subjects' perspective of Confronting COPD International Survey. Eur Respir J 2002;20(4):799-805.

25. Di Marco F, Verga M, Reggente M, Maria Casanova F, Santus P, Blasi F, et al. Anxiety and depression in COPD patients: the roles of gender and disease severity. Respir Med 2006;100(10):1767-1774.

26. Rabe KF, Hurd S, Anzueto A, Barnes PJ, Buist SA, Calverley P, et al. Global strategy for the diagnosis, management, and prevention of 


\section{COPD Management in a Community-Based Setting}

chronic obstructive pulmonary disease: GOLD executive summary. Am J Respir Crit Care Med 2007;176(6):532-555.

27. Mannino DM, Buist AS. Global burden of COPD: risk factors, prevalence, and future trends. Lancet 2007;370(9589):765-773.

28. Willemse BW, ten Hacken NH, Rutgers B, Lesman-Leegte IG, Postma DS, Timens W. Effect of 1-year smoking cessation on airway inflammation in COPD and asymptomatic smokers. Eur Respir J 2005; 26(5):835-845.

29. Simmons MS, Connett JE, Nides MA, Lindgren PG, Kleerup EC, Murray RP, et al. Smoking reduction and the rate of decline in $\mathrm{FEV}_{1}$ : results from the Lung Health Study. Eur Respir J 2005;25(6):10111017.

30. Au DH, Bryson CL, Chien JW, Sun H, Udris EM, Evans LE, Bradley KA. The effects of smoking cessation on the risk of chronic obstructive pulmonary disease exacerbations. J Gen Intern Med 2009; 24(4):457-463.

31. Godtfredsen NS, Lam TH, Hansel TT, Leon ME, Gray N, Dresler C, et al. COPD-related morbidity and mortality after smoking cessation: status of the evidence. Eur Respir J 2008;32(4):844-853.

32. Celli BR. Update on the management of COPD. Chest 2008;133(6): 1451-1462.

33. Zhou Y, Wang C, Yao W, Chen P, Kang J, Huang S, et al. COPD in Chinese nonsmokers. Eur Respir J 2009;33(3):509-518.

34. Hu G, Zhou Y, Tian J, Yao W, Li J, Li B, Ran P. Risk of COPD from exposure to biomass smoke: a Metaanalysis. Chest 2010;138(1):2031.
35. Mikkelsen RL, Middelboe T, Pisinger C, Stage KB. Anxiety and depression in patients with chronic obstructive pulmonary disease (COPD): a review. Nord J Psychiatry 2004;58(1):65-70.

36. Wilson I. Depression in the patient with COPD. Int J Chron Obstruct Pulmon Dis 2006;1(1):61-64.

37. Bösch D, Feierabend M, Becker A. COPD outpatient education programmer (ATEM) and BODE index. Pneumologie 2007;61(10):629635 .

38. Kunik ME, Braun U, Stanley MA, Wristers K, Molinari V, Stoebner $\mathrm{D}$, Orengo CA. One session cognitive behavioral therapy for elderly patients with chronic obstructive pulmonary disease. Psychol Med 2001;31(4):717-723.

39. Kunik ME, Veazey C, Cully JA, Souchek J, Graham DP, Hopko D, et al. COPD education and cognitive behavioral therapy group treatment for clinically significant symptoms of depression and anxiety in COPD patients: a randomized controlled trial. Psychol Med 2008; 38(3):385-396

40. Wongsurakiat P, Maranetra KN, Wasi C, Kositanont U, Dejsomritrutai W, Charoenratanakul S. Acute respiratory illness in patients with COPD and the effectiveness of influenza vaccination: a randomized controlled study. Chest 2004;125(6):2011-2020.

41. Yu WC, Tai EL, Fu SN, Kwong KC, Yeung YC, Chang Y, et al. Treatment of patients with chronic obstructive pulmonary disease as practised in a defined Hong Kong community: a cross-sectional pilot survey. Hong Kong Med J 2011;17(4):306-314. 